\title{
Re-audit of bedside glucose monitoring of inpatients on glucocorticoids: have we improved?
}

\author{
DAVID BAWDEN, RANU BARAL, SMRITI GAUR, REBECCA ROGERS, KETAN DHATARIYA
}

Elsie Bertram Diabetes Centre, Norfolk and Norwich University Hospital NHS Foundation Trust, Norwich, Norfolk, UK

Key words: diabetes, glucocorticoids, hyperglycaemia, monitoring

Exogenous glucocorticoids are commonly prescribed medication used across a large variety of medical and surgical specialities for their excellent anti-inflammatory properties. However, the advantages to using glucocorticoids must be balanced against their many well described adverse effects. ${ }^{1}$ In particular, excessive glucocorticoid use contributes to whole-body insulin resistance that can result in hyperglycaemia in those known to have diabetes, or the development of steroid-induced diabetes, which may or may not be transient. $^{2}$

In 2014, colleagues at our institution audited glucocorticoid use and adherence to recommended glucose monitoring guidance. ${ }^{3} \mathrm{At}$ that time $12.8 \%(n=120)$ of the inpatient population were on glucocorticoids with only $20.8 \%$ of those $(n=25)$ having their glucose monitored. Of those 25 people, 13 had pre-existing diabetes. Since then, national guidelines on the management of hyperglycaemia and glucocorticoid therapy have been published. ${ }^{4}$ These guidelines recommended glucose monitoring regimens for those taking glucocorticoids. They stated that those who were known to have diabetes should have their glucose tested four times a day. Those without a diagnosis of diabetes should have either pre-lunch or pre-evening meal testing. If they develop a capillary glucose above $12.0 \mathrm{mmol} / \mathrm{L}$, then testing should be four times a day.

We re-audited glucose monitoring in those adult inpatients on glucocorticoids at our institution on a single day in January 2020. We had 945 adult beds occupied on the day of the cross-sectional audit. Those with and without diabetes over 18 years old on glucocorticoids were identified using our patient administration system, electronic pathology system and electronic prescribing and medicines administration system (JAC ${ }^{\circledR}$, WellSky Ltd, Basildon, Essex, UK). We excluded those on the children's ward, maternity wards or in the emergency department.

Table 1 shows the results, and compares them with the data from 2014. We found that $8.9 \%(n=84)$ of inpatients were receiving exogenous steroids. Of these, $48 \%(n=40)$ were having their glucose monitored. $87.5 \%(n=14)$ of those with diabetes were having four times a day testing. However, only $37 \%(n=25)$ of those with no previous diagnosis of diabetes were having the advised once daily glucose monitoring. We did not analyse which of these individuals should have been having four times a day testing, nor did we set out to identify any individuals with newly diagnosed
Table 1 Results of re-audit of inpatient glucose monitoring of patients on steroids

\begin{tabular}{|c|c|c|c|c|c|}
\hline & & 20 & & 20 & \\
\hline & & $\mathbf{n}$ & $\%$ & $\mathrm{n}$ & $\%$ \\
\hline Female & & 68 & 57 & 45 & 54 \\
\hline Male & & 52 & 43 & 39 & 46 \\
\hline Diabetes & Yes & 16 & 13 & 16 & 19 \\
\hline & No & 104 & 87 & 68 & 81 \\
\hline Steroid & Dexamethasone & 16 & 13 & 17 & 14 \\
\hline & Hydrocortisone & 4 & 3 & 6 & 7 \\
\hline & Methylprednisolone & & & 6 & 7 \\
\hline & Prednisolone & 99 & 83 & 55 & 72 \\
\hline Indication & Respiratory & 76 & 63 & 24 & 29 \\
\hline & MSK/Rheum & 21 & 18 & 18 & 21 \\
\hline & Oncology & 12 & 10 & 8 & 10 \\
\hline & Other/unknown & 11 & 9 & 34 & 30 \\
\hline Duration & $<10$ days & 56 & 47 & 29 & 24 \\
\hline & $>10$ days & 64 & 53 & 55 & 76 \\
\hline Monitoring & Yes & 25 & 21 & 40 & 48 \\
\hline & No & 95 & 79 & 44 & 52 \\
\hline
\end{tabular}

diabetes or steroid-induced diabetes in those who were not known to have diabetes prior to admission.

This re-audit has shown some improvement in glucose monitoring of those taking steroids as an inpatient. However, it is still less than half of the target population and not in line with the Joint British Diabetes Societies for Inpatient Care (JBDS-IP) guidance published in 2014. It is possible that the improvement in monitoring since our last audit is due to an increased awareness among medical and nursing staff of the impact of glucocorticoids on glucose concentrations and the potential consequences. However, this is just speculation.

This re-audit was undertaken because our institution had recently introduced electronic prescribing. The electronic platform allows alerts to be added when high-risk medications are used. Despite the poor performance in glucose monitoring shown by our previous audit, our pharmacy would not add an alert reminding those who were dispensing the glucocorticoids (ie, trained ward nurses) to conduct bedside capillary glucose monitoring unless we 
could show that it was not being carried out already in accordance with the JBDS-IP guidance adopted by our hospital. Despite the improvement in monitoring frequency, it remains suboptimal and, as a result of the current work, our pharmacy has agreed to introduce the alert once the pandemic has resolved. We aim to re-audit the impact of this in due course.

Conflict of interest Professor Dhatariya is one of the lead authors on the JBDS guideline entitled 'Management of hyperglycaemia and steroid (glucocorticoid) therapy: a guideline from the Joint British Diabetes Societies (JBDS) for Inpatient Care group'.

Funding None

\section{References}

1. British Medical Association, Royal Pharmaceutical Society of Great Britain. British National Formulary. London, 2020.
2. Geer EB, Islam J, Buettner C. Mechanisms of glucocorticoid-induced insulin resistance. Endocrinol Metab Clin North Am 2014:43:75-102. https://doi.org/10.1016/j.ecl.2013.10.005

3. Narwani V, Swafe L, Stavraka C, Dhatariya K. How frequently are bedside glucose levels measured in hospital inpatients on glucocorticoids? Clin Med 2014;14:327-8. https://doi.org/10.7861/clinmedicine.14-3-326a

4. Roberts A, James J, Dhatariya K, et al. Management of hyperglycaemia and steroid (glucocorticoid) therapy: a guideline from the Joint British Diabetes Societies (JBDS) for Inpatient Care group. Diabet Med 2018; 35:1011-17. https://doi.org/10.1111/dme.13675

Correspondence: Professor Ketan Dhatariya Elsie Bertram Diabetes Centre, Norfolk and Norwich University Hospital NHS Foundation Trust, Colney Lane, Norwich, Norfolk NR4 7UY, UK E-mail: ketan.dhatariya@nnuh.nhs.uk

Br J Diabetes 2021:21:156-157 https://doi.org/10.15277/bjd.2021.279

\title{
Fixed-dose combination: beware of its limitations
}

\author{
NEELESH GUPTA, ${ }^{1}$ MOHAMMED ELKHAZENDAR, ${ }^{2}$ RAJEEV GUPTA ${ }^{3}$
}

1 Department of Medicine, Nazareth Hospital, Philadelphia, PA, USA

2 Clinical Sciences Department, College of Medicine, University of Sharjah, United Arab Emirates

${ }^{3}$ Department of Cardiology, Mediclinic Al Jowhara Hospital, Al Ain, United Arab Emirates

We read with great interest the editorial detailing the likelihood of cardiovascular (CV) benefit from the triple fixed-dose combination (FDC) therapy for patients with type 2 diabetes mellitus. ${ }^{1}$ Sodiumglucose cotransporter-2 inhibitors (SGLT2i) are preferred in view of their documented CV benefits. The FDC pill containing metformin, dipeptidyl peptidase-4 (DPP-4) inhibitor and SGLT2i has been approved by the US FDA. However, the CV protective effects of SGLT2i may be less when combined with metformin. For instance, with canagliflozin, the risk of $\mathrm{CV}$ death and hospitalisation was reduced by $36 \%$ in metformin non-users versus $12 \%$ in metformin users $(p=0.03){ }^{2}$ Although this may well be a type 1 statistical error, notably, a similar trend was also observed with empagliflozin ( $53 \%$ vs $32 \%, p=0.01) .^{3}$ A possible explanation may be that the use of metformin has its well-documented CV benefits; thus, additional benefits were minimised with the added use of SGLT2i. ${ }^{4}$ Interestingly, the addition of a DPP-4 inhibitor to metformin resulted in improved CV outcomes compared with the initiation of DPP-4 inhibitor in non-metformin users. ${ }^{5}$ Therefore, the issue deserves further investigation, perhaps as an endpoint in a future CV outcome trial with an SGLT2i.

\section{Conflict of interest None. Funding None}

\section{References}

1. Ryder REJ, Abdul-Ghani MA, DeFronzo RA. Diabetes medications with cardiovascular protection: the likelihood of benefit from combination therapy increases further following new evidence during 2020. Br J Diabetes 2020; 20(2):85-8. https://doi.org/10.15277/bjd.2020.276

2. Rådholm K, Figtree G, Perkovic V, et al. Canagliflozin and heart failure in type 2 diabetes mellitus: results from the CANVAS program. Circulation 2018;138(5):458-68. https://doi.org/10.1161/circulationaha.118.034222

3. Inzucchi SE, Fitchett $D$, Jurišić-Eržen $D$, et al. Are the cardiovascular and kidney benefits of empagliflozin influenced by baseline glucose-lowering therapy? Diabetes Obes Metab 2020;22(4):631-9. https://doi.org/10.1111/ dom. 13938

4. Han $Y$, Xie H, Liu Y, et al. Effect of metformin on all-cause and cardiovascular mortality in patients with coronary artery diseases: a systematic review and an updated meta-analysis. Cardiovasc Diabetol 2019:18(1):96. https://doi.org/10.1186/s12933-019-0900-7

5. Crowley MJ, Gokhale M, Pate V , et al. Impact of metformin use on the cardiovascular effects of dipeptidyl peptidase-4 inhibitors: an analysis of Medicare claims data from 2007 to 2015. Diabetes Obes Metab 2019:21(4): 854-65. https://doi.org/10.1111/dom.13589

Correspondence: Dr Mohammed Elkhazendar Clinical Sciences Department, College of Medicine, University of Sharjah, United Arab Emirates E-mail: modnnkh@yahoo.com

Br J Diabetes 2021;21:157 https://doi.org/10.15277/bjd.2021.289 